\title{
A Coordination Chemistry Approach to Fine-Tune the Physicochemical Parameters of Lanthanide Complexes Relevant to Medical Applications
}

\author{
Mariane Le Fur, ${ }^{[\mathrm{a}]}$ Enikő Molnár, ${ }^{[\mathrm{b}]}$ Maryline Beyler, ${ }^{[\mathrm{a}]}$ Ferenc K. Kálmán, ${ }^{[\mathrm{b}]}$ Olivier Fougère,${ }^{[\mathrm{c}]}$ David \\ Esteban-Gómez, ${ }^{[\mathrm{d}]}$ Olivier Rousseaux ${ }^{[\mathrm{c}]}$ Raphaël Tripier, ${ }^{[\mathrm{a}]}$ Gyula Tircsó, ${ }^{*,[\mathrm{~b}]}$ and Carlos Platas- \\ Iglesias $^{*,[d]}$
}

Dedicated to Professors Carlos F. G. C. Geraldes and Lothar Helm on the occasion of their retirement

\begin{abstract}
The geometric features of two pyclen-based ligands possessing identical donor atoms but different site organization have a profound impact in their complexation properties toward lanthanide ions. The ligand containing two acetate groups and a picolinate arm arranged in a symmetrical fashion (L1) forms a $\mathrm{Gd}^{3+}$ complex being two orders of magnitude less stable than its dissymmetric analogue GdL2. Besides, GdL1 experiences a much faster dissociation following the acid-catalyzed mechanism than GdL2. On the contrary, GdL1 exhibits a lower exchange rate of the coordinated water molecule compared to GdL2. These very different properties are related to different strengths of the Gd-ligand bonds associated to steric effects, which hinder the coordination of a water molecule in GdL2 and the binding of acetate groups in GdL1.
\end{abstract}

The lanthanides are a group of elements with very important technological applications often associated to their peculiar optical and magnetic properties. Several of these applications require the input of coordination chemistry to obtain lanthanide complexes with the desired properties, particularly regarding the design of optical ${ }^{[1]}$ and magnetic ${ }^{[2,3]}$ probes for medical diagnosis and bioanalytical assays. The lanthanide(III) $\left(\mathrm{Ln}^{3+}\right)$ ions represent a series of hard Lewis acids that have a strong preference to form stable complexes with polydentate ligands containing hard oxygen donor atoms (i. e. polyaminopolycarboxylate ligands), generally adopting high coordination numbers (typically 8-9). The $\mathrm{Ln}^{3+}$-ligand interaction is considered to be largely electrostatic in origin, so that the metal coordination environment is dictated by a subtle interplay between electrostatic interactions and steric constraints. ${ }^{[4]}$ As a

[a] Dr. M. Le Fur, Dr. M. Beyler, Prof. R. Tripier Université de Bretagne Occidentale, UMR-CNRS 6521, UFR des Sciences et Techniques, 6 avenue Victor le Gorgeu, C.S. 93837 29238 Brest Cedex 3, France

[b] E. Molnár, Dr. G. Tircsó, Dr. F. K. Kálmán Department of Inorganic and Analytical Chemistry University of Debrecen H-4010 Debrecen, Egyetem tér 1, Hungary E-mail: gyula.tircso@science.unideb.hu

[c] O. Fougère, $\mathrm{Dr} O$ Rousseaux Guerbet Group, Centre de Reserche d'Aulnay-sous-Bois, BP 57400 95943 Roissy CdG Cedex, France

[d] Dr. D. Esteban-Gómez, Dr. C. Platas-Iglesias Centro de Investigacións Científicas Avanzadas (CICA) and Departamento de Química, Facultade de Ciencias, Universidade da Coruña, 15071 A Coruña, Galicia, Spain. E-mail: carlos.platas.iglesias@udc.es

Supporting information for this article is given via a link at the end of the document. result, there has been a limited success in establishing relationships between the structures and properties of $\mathrm{Ln}^{3+}$ complexes in solution or designing complexes with predetermined properties, though some major advances were reported for some specific systems ${ }^{[5]}$ or with respect to some specific properties (i. e. relaxivity). ${ }^{[6]}$ For instance, the water exchange kinetics in $\mathrm{Ln}^{3+}$ (often $\mathrm{Gd}^{3+}$ ) complexes were accelerated by increasing the steric compression around the water binding site, which can be achieved by replacing carboxylate groups by bulkier phosphonate units, ${ }^{[7]}$ or by increasing the size of one of the chelate rings from 5 to 6membered. ${ }^{[8]}$ On the contrary, water exchange was decelerated by replacing carboxylate groups by amide donors, ${ }^{[9]}$ as this increses the positive charge of the complex resulting in a stronger $\mathrm{Ln}^{3+}-\mathrm{O}_{\text {water }}$ bond. Increasing the size of the chelate and replacing carboxylate groups by amides is detrimental for complex stability, although DOTA-tetraamide $\mathrm{Ln}^{3+}$ complexes were found to possess higher kinetic inertness than the parent DOTA complexes. ${ }^{[10,11]}$ Some structural modification on macrocyclic cyclen-based ligands were also found to accelerate the dissociation of the $\mathrm{Gd}^{3+}$ complexes, demonstrating that the kinetic inertness of some macrocyclic complexes cannot be generalized to all macrocyclic chelates. ${ }^{[12]}$
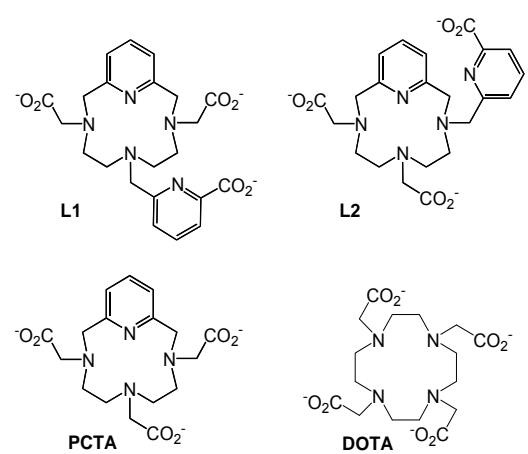

Scheme 1. Ligands discussed in the present work.

Herein we show that subtle changes in the arrangement of the ligand donor atoms have a deep impact in important features of the complexes, such as their thermodynamic stabilities and dissociation and solvent exchange kinetics. For this purpose, we have chosen the $\mathrm{Gd}^{3+}$ complexes of the recently reported macrocyclic ligands L1 and L2 ${ }^{[13]}$ which differ in the relative positions of the pendant arms attached to the pyclen (12-py-N4) 
unit (Scheme 1). We have selected $\mathrm{Gd}^{3+}$ because of the relevance of complexes of this metal ion as contrast agents in MRI. ${ }^{[2]}$ Besides, the paramagnetic properties of $\mathrm{Gd}^{3+}$ allow a detailed characterization of complexes of this metal ion using NMR relaxometry. ${ }^{[14]}$ The GdL1 and GdL2 complexes, as well as the corresponding $\mathrm{Eu}^{3+}$ and $\mathrm{Yb}^{3+}$ analogues, were obtained in excellent yields $(89-98 \%)$ by reaction of the ligand with the corresponding lanthanide chloride salt in water at $\mathrm{pH} 5$ (see Supporting Information).
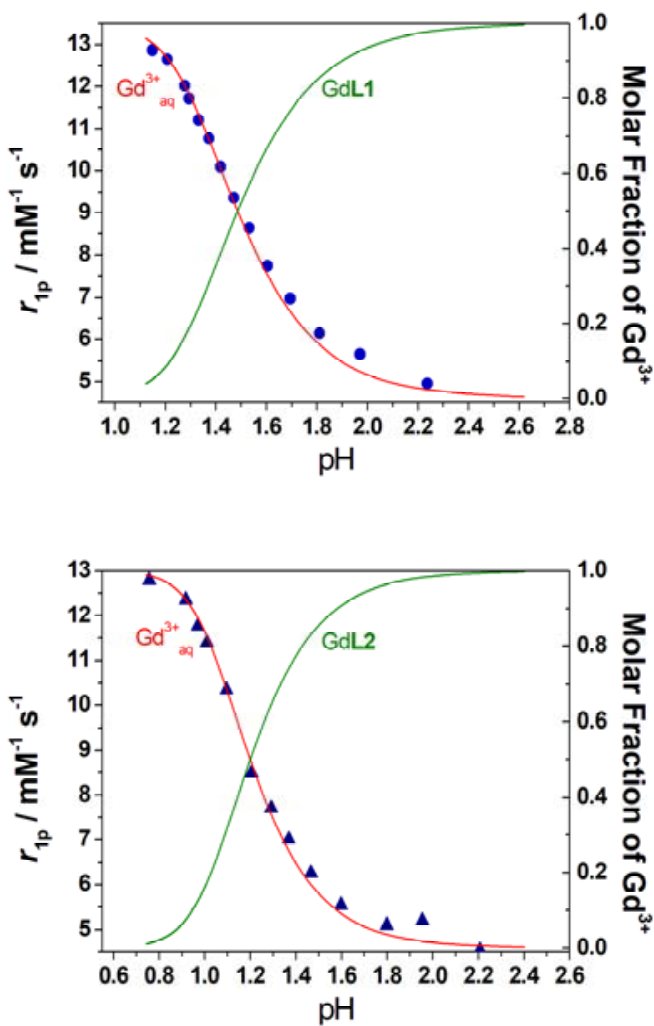

Figure 1. Proton relaxivities ( $\left.r_{10}\right)$ of GdL1 (top) and GdL2 (bottom) as function of proton concentration. The solid lines show the species distributions calculated with the stability constants given in Table $1\left(25^{\circ} \mathrm{C}, 0.15 \mathrm{M} \mathrm{NaCl}\right)$.

Our investigation was initiated by determining the thermodynamic stability constants of the GdL1 and GdL2 complexes using the relaxometric technique. ${ }^{[14]}$ The relaxivity $\left(r_{1 \mathrm{p}}\right)$ of the complexes recorded at $20 \mathrm{MHz}$ and $25^{\circ} \mathrm{C}$ is typical of small $\mathrm{Gd}^{3+}$ complexes containing a coordinated water molecule (Table 1). Below $\mathrm{pH} \sim 2$ the relaxivity of aqueous solutions of the complexes increases as a result of complex dissociation and formation of $\left[\mathrm{Gd}\left(\mathrm{H}_{2} \mathrm{O}\right)_{8}\right]^{3+}$, which shows a relaxivity of 13.5 $\mathrm{mM}^{-1} \mathrm{~s}^{-1}$ at $20 \mathrm{MHz}$ and $25^{\circ} \mathrm{C}$ (Figure 1). ${ }^{[15]}$ One can notice that in the case of GdL2 a lower $\mathrm{pH}$ is required to provoke the full dissociation of the complex. Given that the two ligands present very similar basicities, ${ }^{[6]}$ this is an indication that the complex of L2 presents a higher thermodynamic stability than that of L1. The analysis of the relaxivity data provide the stability constants reported in Table 1. The results of this studies show that the stability constant of GdL1 is two orders of magnitude higher than that of GdPCTA (also reported here), ${ }^{[16]}$ but two orders of magnitude lower than that of GdL2.

Table 1. Relaxivities, stability constants, dissociation rate constants $\left(k_{1}\right)$ and water exchange rates $\left(k_{\mathrm{ex}}{ }^{298}\right)$ determined for GdL1 and GdL2.

\begin{tabular}{llll}
\hline Parameter & $\mathrm{GdL1}^{[\mathrm{a}]}$ & $\mathrm{GdL2}^{[\mathrm{a}]}$ & $\mathrm{GdPCTA}$ \\
\hline$r_{1 \mathrm{p}} / \mathrm{mM}^{-1} \mathrm{~s}^{-1[\mathrm{~b}]}$ & 4.74 & 4.95 & $7.09^{[\mathrm{a}]}$ \\
$\log K_{\mathrm{GdL}}$ & $20.49 \pm 0.02$ & $22.37 \pm 0.03$ & $18.28 \pm 0.03^{[\mathrm{a}]}$ \\
$\mathrm{pGd}^{[\mathrm{c}]}$ & 17.74 & 20.25 & $16.62^{[\mathrm{a}]}$ \\
$k_{1} / \mathrm{M}^{-1} \mathrm{~s}^{-1}[\mathrm{~d}]$ & $(6.9 \pm 0.1) \times 10^{-4}$ & $(2.13 \pm 0.08) \times 10^{-4}$ & $5.08 \times 10^{-4}$ \\
$t_{1 / 2} / \mathrm{min}^{[\mathrm{e}]}$ & 167 & 542 & 231 \\
$k_{\mathrm{ex}}{ }^{298} / 10^{6} \mathrm{~s}^{-1}$ & $1.08 \pm 0.02$ & $22.5 \pm 2.3$ & 14.3 \\
$\tau_{\mathrm{m}}{ }^{298} / \mu \mathrm{s}$ & $926 \pm 17$ & $44 \pm 5$ & 70 \\
$\Delta H^{\ddagger} / \mathrm{kJ} \mathrm{mol}^{-1}$ & $28.6 \pm 0.6$ & $37.5 \pm 0.2$ & 45 \\
\hline
\end{tabular}

[a] This work. [b] At $20 \mathrm{MHz}, 25^{\circ} \mathrm{C}$. [c] Calculated at $\mathrm{pH}=7.4$ using $\mathrm{Cligand}_{\text {lign }}=$ $10^{-5} \mathrm{M}$ and $\mathrm{c}_{\mathrm{GGd}}=10^{-6} \mathrm{M}$. [d] Rate constants characterizing the proton-assisted dissociation of the complexes. Data for GdPCTA was taken from reference [17] and correspond to the Eu complex. [e] Half-lives calculated from the rate constants $0.1 \mathrm{M}$ proton concentration.
Figure 2. Pseudo-first-order rate constants $\left(k_{\text {obs }}\right)$ measured for the acidassisted dissociation of GdL1 (circles) and GdL2 (triangles) as a function of proton concentration. The solid lines correspond to the linear fit of the data.

Given the results obtained from the thermodynamic studies, we next analyzed whether these complexes present significantly different dissociation kinetics. The dissociation of $\mathrm{Ln}^{3+}$ complexes with macrocyclic ligands generally takes place following the acid-catalyzed mechanism. ${ }^{[17]}$ Thus, the dissociation of the complexes was followed under pseudo-first order conditions (proton concentration range $0.1-1 \mathrm{M}$ ) by following the changes in the UV absorption band of the picolinate group at $279 \mathrm{~nm}$. The observed rate constants $\left(k_{\mathrm{obs}}\right)$ show a linear dependence with proton concentration (Figure 2). The rate constants $\left(k_{\mathrm{obs}}\right)$ of GdL2 are clearly lower than those of GdL1 at a given proton concentration, indicating that the complex of L2 presents a higher kinetic inertness. The kinetic data was analyzed by fitting the experimental data to $k_{\mathrm{obs}}=k_{0}+$ $k_{1}\left[\mathrm{H}^{+}\right]$, where $k_{0}$ and $k_{1}$ represent the rate constants characterizing the spontaneous and proton-assisted dissociation, respectively. The linear least-squares fits of the 
data provided very small values for $k_{0}$ with large statistical errors, indicating that the spontaneous dissociation does not contribute to the overall dissociation reaction under the conditions applied. The $k_{1}$ values obtained (Table 1 ) reveal a considerably faster proton-assisted dissociation of GdL1 compared to GdL2, the latter showing a half-life $\sim 3$ times longer at a proton concentration of $0.1 \mathrm{M}$. The GdL2 complex is considerably more inert than EuPCTA (Scheme 1), for which an acid-catalyzed rate constant of $5.08 \times 10^{-4} \mathrm{M}^{-1} \mathrm{~s}^{-1}$ was reported. ${ }^{[17]}$ Besides being considerably more inert, GdL2 also presents much faster complexation kinetics than GdL1 (Supporting Information).

The absorption spectra of the $\mathrm{Eu}^{3+}$ complexes of L1 and L2 recorded in $\mathrm{H}_{2} \mathrm{O}$ solution show an absorption band with a maximum at $274 \mathrm{~nm}$ characteristic of the pyridyl chromophores (Supporting Information). ${ }^{[18]}$ The emission spectra were recorded in $\mathrm{H}_{2} \mathrm{O}$ and $\mathrm{D}_{2} \mathrm{O}$ solutions of the $\mathrm{Eu}^{3+}$ complexes $(\mathrm{pH} 7.45$, tris buffer). The corresponding excitation spectra recorded upon analyzing at the maxima of the metal-centered emission are very similar to the corresponding absorption spectra. This indicates sensitization of the metal ion through energy transfer from the ligand to the metal ion. ${ }^{[19]}$ The complexes present the red emission associated to the ${ }^{5} D_{0} \rightarrow{ }^{7} F_{J}(J=0-4)$ transitions of this metal ion. A detailed comparison of the emission spectra recorded for EuL1 and EuL2 evidences different splitting patterns of the $\Delta J=1$ and the hypersensitive $\Delta J=2$ transitions (Supporting Information), reflecting significantly different coordination environments in the two complexes. The emission lifetimes of the $\mathrm{Eu}^{3+}\left({ }^{5} \mathrm{D}_{0}\right)$ excited states were measured in $\mathrm{H}_{2} \mathrm{O}$ and $\mathrm{D}_{2} \mathrm{O}$ solutions to determine the number of water molecules coordinated to the metal ion (Supporting Information). These studies provided hydration numbers close to 1 using the methodology proposed by Beeby, ${ }^{[20]}$ which indicates the presence of a water molecule coordinated to the metal ion.

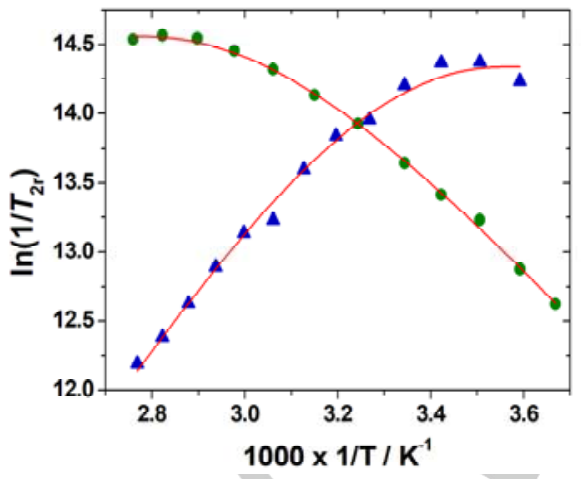

Figure 3. Reduced transverse ${ }^{17} \mathrm{O}$ relaxation rates measured at $9.4 \mathrm{~T}(\mathrm{pH}=$ 7.2) for GdL1 (circles) and GdL2 (triangles). The solid lines correspond to the fits of the data as described in the text. The reduced relaxation rates are defined as $\left.1 / T_{2 \mathrm{r}}=\left[1 / \mathrm{C}_{\mathrm{Gd}} / 55.5\right)\right]\left[1 / T_{\mathrm{i}}-1 / T_{\mathrm{iA}}\right]$, where $T_{\mathrm{i}}$ and $T_{2 \mathrm{~A}}$ are the paramagnetic and diamagnetic relaxation times and $c_{\mathrm{Gd}}$ is the concentration of the complex.
The water exchange rates of the coordinated water molecules in the GdL1 and GdL2 complexes were determined by measuring the ${ }^{17} \mathrm{O}$ NMR transverse relaxation rates of aqueous solutions of the complexes at different temperatures (see Supporting Information for details). A qualitative analysis of the reduced transverse relaxation rates $\left(1 / T_{2 r}\right)$ can be performed using the following simplified equation (Eq [1]) that neglects the chemical shift difference between bound and bulk water: ${ }^{[21]}$

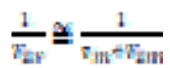

In this equation, $\tau_{m}$ is the mean residence time of a water molecule in the inner coordination sphere of $\mathrm{Gd}^{3+}$ and $T_{2 \mathrm{~m}}$ is the transverse relaxation time of the bound water molecule. Generally $\tau_{\mathrm{m}}$ and $T_{2 \mathrm{~m}}$ present an opposite temperature dependence, as water exchange is accelerated with increasing temperature $\left(\tau_{\mathrm{m}}=1 / k_{\mathrm{ex}}\right.$ decreases $)$ while $T_{2 \mathrm{~m}}$ increases with increasing temperature. The ${ }^{17} \mathrm{O}$ NMR data obtained for GdL1 and GdL2 show opposite temperature dependences, which evidences very different water exchange rates for these complexes. The $1 / T_{2 r}$ values increase with increasing temperature for GdL1, which shows that $\tau_{\mathrm{m}}$ dominates the denominator of Eq [1], pointing to a rather slow water exchange.

The ${ }^{17} \mathrm{O}$ NMR transverse relaxation rates were fitted using standard procedures. ${ }^{[22]}$ In this analysis we fixed the ${ }^{17} \mathrm{O}$ hyperfine coupling constant to the standard value of $-3.8 \times 10^{6}$ rad $s^{-1} .^{[15,18]}$ The longitudinal electron spin relaxation rate $1 / T_{1 \mathrm{e}}$ was assumed to follow an Arrhenius-type temperature dependence with an activation energy of $1 \mathrm{~kJ} \mathrm{~mol}^{-1}$. $^{[15]}$ The parameters obtained from the least-squares fit of the data are shown in Table 1, while the fitted curves are presented in Figure 3 . The water exchange of the coordinated water molecule was found to be 20 times faster for GdL2 compared to GdL1, highlighting that the different arrangement of the donor atoms of the ligand around the metal ion has a striking impact in the exchange rate of the coordinated water molecule. The water exchange rate obtained for GdL1 is about four times slower than that of GdDOTA $\left(k_{\mathrm{ex}}{ }^{298}=4.1 \times 10^{6} \mathrm{~s}^{-1}\right),{ }^{[15]}$ while the exchange rate obtained for GdL2 is faster than the bis-aquated GdPCTA complex $\left(k_{\mathrm{ex}}{ }^{298}=14.3 \times 10^{6} \mathrm{~s}^{-1}\right) \cdot{ }^{[23]}$ The analysis of the ${ }^{17} \mathrm{O}$ NMR data also provided the relaxation times of the electron spin, which turned out to be similar for GdL1 and GdL2 $\left(T_{1 \mathrm{e}}{ }^{298}=49.4\right.$ \pm 1.4 and $35.9 \pm 2.7 \mathrm{~ns}$, respectively, at $298 \mathrm{~K}$ and $9.4 \mathrm{~T}$ ).

The structure of the YbL2 complex in the solid state was established using single-crystal $\mathrm{X}$-ray diffraction measurements. The crystal structure (Figure 4) shows eight coordination of the metal ion by the ligand, with coordination number nine being completed by the presence of an inner-sphere water molecule. The metal coordination environment can be best described as tricapped trigonal prismatic, where the capping tripod is defined by the coordinated water molecule $\mathrm{O} 1$ and the amine nitrogen atoms N3I and N1I. Atoms O3I, O5I and N4I define the upper tripod while $\mathrm{O} 1 \mathrm{I}, \mathrm{N} 2 \mathrm{I}$ and $\mathrm{N} 5 \mathrm{I}$ delineate the lower tripod (see labelling Figure 4). 

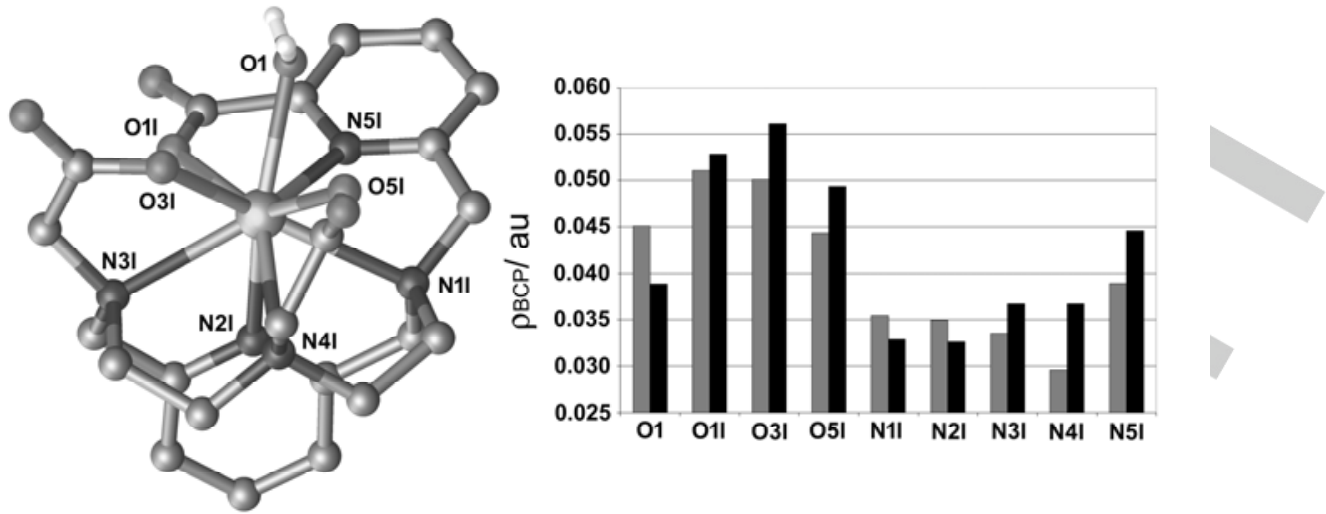

Figure 4. Left: X-ray structure of YbL2 with atom numbering. Right: Electron densities at the bond critical points obtained with DFT calculations for GdL1 (grey bars) and GdL2 (black bars).

To rationalize the very different properties of the GdL1 and GdL2 complexes we performed DFT calculations using standard methods (See Supporting Information). ${ }^{[17]}$ The theoretical structure of GdL2 is very similar to that observed in the solid state for the $\mathrm{Yb}^{3+}$ analogue. A comparison of the bond distances of the metal coordination environment calculated for GdL1 and GdL2 reveals significant differences. In particular, the distance involving the coordinated water molecule is clearly longer in GdL2 (Gd-O1 = $2.519 \AA)$ than in GdL1 $(2.450 \AA)$. It is also worth noting that the average $\mathrm{Gd} \cdots \mathrm{H}$ distances involving the coordinated water molecules are virtually identical in the two complexes $(3.010 \AA)$, as a result of a different orientation of the $\mathrm{HOH}$ plane of the coordinated water molecule with respect to the Gd-O1 vector. Another important difference concerns the Gd-O3l distances (2.458 and $2.407 \AA$ for GdL1 and GdL2, respectively), which suggest a weaker coordination of an acetate arm in GdL1. A more detailed analysis of the $\mathrm{Gd}^{3+}$ coordination environment was carried out by calculating the electron density $(\rho)$ at the bond critical points (BCPs). Both $\rho_{B C P}$ and ELF $F_{B P C}$ can be correlated to the strength of the Gd-donor bonds. ${ }^{[24]}$ The results (Figure 4, see also Supporting Information) show that the $\mathrm{Gd}-\mathrm{O}$ bonds are generally stronger than the $\mathrm{Gd}-\mathrm{N}$ ones, as would be expected. The values of $\rho_{\mathrm{BCP}}$ calculated for the $\mathrm{Gd}-\mathrm{O}$ bonds involving carboxylate oxygen atoms (011, $\mathrm{O} 3 \mathrm{I}$ and $\mathrm{O} 5 \mathrm{I})$ evidence stronger bonds in the case of GdL2 compared to GdL1 in line with the higher stability of the former. However, the innersphere water molecule is more tightly bound in GdL1, resulting in a lower water exchange rate.

In conclusion, we have shown that subtle changes in the arrangement of the donor atoms around the central metal ion have profound consequences in important properties of lanthanide complexes, including: i) Their thermodynamic stability; ii) Complexation kinetics; iii) Kinetic inertness with respect to complex dissociation, and iv) The lability of coordinated water molecules. All these parameters must be optimized to develop efficient diagnostic and therapeutic agents relying on the use of $\operatorname{Ln}(\mathrm{III})$ ions. This effect is related to the high coordination numbers adopted by the $\mathrm{Ln}^{3+}$ ions and the fact that some donor atoms might be hindered by the environment. In GdL2 the coordinated water binding site is sterically compressed, which results in a fast water exchange. However, in GdL1 the oxygen atoms of carboxylate groups provide weaker interactions with the metal ion, which results in a lower thermodynamic stability. The faster proton-assisted dissociation kinetics of GdL1 is likely caused by the protonation of the weakly coordinated carboxylate, which triggers complex dissociation. A similar effect is probably responsible for the different water exchange rates and stabilities observed for the bis-hydrated Gd(DTTA$\mathrm{Me})^{-}$regioisomers (DTTA-Me $=N$-methyl diethylenetriamine tetraacetate), as the complex with the methyl group on the terminal nitrogen is two orders of magnitude more stable than the derivative with the methyl group at the central nitrogen, ${ }^{[25,26]}$ while the terminal $\mathrm{N}-\mathrm{Me}$ isomer has about 100 -fold slower water exchange kinetics compared to the central N-Me isomer. ${ }^{[26,27]}$ Thus, the results of this study provide the basis for the rational design and prediction of the geometric features of multidentate ligands for efficient lanthanide complexation, an issue with great potential impact in many areas where the coordination chemistry of the rare-earths is present.

\section{Acknowledgements}

D.E.-G. and C.P.-I. thank Ministerio de Economía y Competitividad (CTQ2016-76756-P) for generous financial support and Centro de Supercomputación of Galicia (CESGA) for providing the computer facilities. R. T. acknowledges the Ministère de l'Enseignement Supérieur et de la Recherche, the Centre National de la Recherche Scientifique. R. T. and O. R. also thanks the Guerbet group and the Association Nationale de la Recherche et de la Technologie for M. L. F's CIFRE fellowship. Gy. T. and K.F.K. are grateful for support granted by the Hungarian National Research, Development and Innovation Office (NKFIH K-120224 project) and for the János Bolyai Research Scholarship of the Hungarian Academy of Sciences. E. T.-M. thanks the scholarship supported by the ÚNKP-17-3 New National Excellence Program of the Ministry of Human Capacities. The research was also supported in a part by the EU 
and co-financed by the European Regional Development Fund under the project GINOP-2.3.2-15-2016-00008.

\section{Keywords: Lanthanides $・$ MRI $・$ Macrocycles $・$ NMR} spectroscopy• Water Exchange

[1] a) J.-C. G. Bünzli, Chem. Rev. 2010, 110, 2729-2755; b) M. Delbianco, V. Sadovnikova, E. Bourrier, G. Mathis, L. Lamarque, J. M. Zwier, D. Parker, Angew. Chem. Int. Ed. 2014, 53, 10718-10722; c) A. T. Bui, M. Beyler, A. Grichine, A. Duperray, J.-C. Mulatier, Y. Guyot, C. Andraud R. Tripier, S. Brasselet, O. Maury, Chem. Commun. 2017, 53, 6005 6008.

[2] The Chemistry of Contrast Agents in Medical Magnetic Resonance Imaging, (Eds. A. E. Merbach, L. Helm, É. Tóth), 2nd ed., Wiley, New York, 2013.

[3] E. Terreno, D. D. Castelli, A. Viale, S. Aime, Chem. Rev. 2010, 110, 3019-3042.

[4] J.-C. G. Bünzli, C. Piguet, Chem. Rev. 2002, 102, 1897-1928.

[5] C. Piguet, Chem. Commun. 2010, 46, 6209-6231.

[6] V. Jacques, S. Dumas, W.-C. Sun, J. S. Troughton, M. T. Greenfield, P. Caravan, Invest. Radiol. 2010, 45, 613-624.

[7] a) J. Kotek, P. Lebduskova, P. Hermann, L. Vander Elst, R. N. Muller C. F. G. C. Geraldes, T. Maschmeyer, I. Lukes, J. A. Peters, Chem. Eur. J. 2003, 9, 5899-5915 ; b) J. Rudovsky, P. Cigler, J. Kotek, P. Hermann, P. Vojtisek, I. Lukes, J. A. Peters, L. Vander Elst, R. N. Muller, Chem. Eur. J. 2005, 11, 2373-2384 ; c) E. Balogh, M. Mato-Iglesias, C. PlatasIglesias, E. Toth, K. Djanashvili, J. A. Peters, A. de Blas, T. RodriguezBlas, Inorg. Chem. 2006, 45, 8719-8728.

[8] a) R. Ruloff, E. Toth, R. Scopelliti, R. Tripier, H. Handel, A. E. Merbach, Chem. Commun. 2002, 2630-2631 ; b) S. Laus, R. Ruloff, E. Toth, A. E. Merbach, Chem. Eur. J. 2003, 9, 3555-3566.

[9] a) M. Woods, S. Aime, M. Botta, J. A. K. Howard, J. M. Moloney, M. Navet, D. Parker, M. Port, O. Rousseaux, J. Am. Chem. Soc., 2000 122, 9781-9792 ; b) F. A. Dunand, R. S. Dickins, D. Parker, A. E. Merbach, Chem. Eur. J. 2001, 7, 5160-5167.

[10] E. Balogh, R. Tripier, P. Fouskova, F. Reviriego, H. Handel, E. Toth, Dalton Trans. 2007, 3572-3581.

[11] A. Pasha, G. Tircso, E. T. Benyo, E. Brücher, A. D. Sherry, Eur. J. Inorg Chem. 2007, 4340-4349
[12] a) M. Polasek, P. Caravan, Inorg. Chem. 2013, 52, 4084-5096 ; b) M. Regueiro-Figueroa, B. Bensenane, E. Ruscsak, D. Esteban-Gomez, L. J. Charbonniere, G. Tircso, I. Toth, A. de Blas, T. Rodriguez-Blas, C. Platas-Iglesias, Inorg. Chem. 2011, 50, 4125-4141.

[13] M. Le Fur, M. Beyler, E. Molnar, O. Fougere, D. Esteban-Gomez, G. Tircso, C. Platas-Iglesias, N. Lepareur, O. Rousseaux, R. Tripier, Chem. Commun. 2017, 53, 9534-9537.

[14] A. Rodriguez-Rodriguez, Z. Garda, E. Ruscsak, D. Esteban-Gómez, A de Blas, T. Rodríguez-Blas, L. M. P. Lima, M. Beyler, R. Tripier, G. Tircso, C. Platas-Iglesias, Dalton Trans. 2015, 44, 5017-5031.

[15] H. D. Powell, O. M. Ni Dhubhghaill, D. Pubanz, L. Helm, Y. Lebedev, W Schlaepfer, A. E. Merbach, J. Am. Chem. Soc. 1996, 118, 9333-9346.

[16] Z. Baranyai, Z. Palinkas, F. Uggeri, A. Maiocchi, S. Aime, E. Brucher, Chem. Eur. J. 2012, 18, 16426-16435.

[17] G. Tircso, Z. Kovacs, A. D. Sherry, Inorg. Chem. 2006, 45, 9269-9280.

[18] N. Chatterton, Y. Bretonniere, J. Pecaut, M. Mazzanti, Angew. Chem. Int. Ed. 2005, 44, 7595-7598; Angew. Chem. 2005, 117, 7767-7770.

[19] M. Latva, H. Takalo, V.-M. Mukkala, C. Matachescu, J.-C. RodriguezUbis, J. Kankare, J. Lumin. 1997, 75, 149-169.

[20] A. Beeby, I. M. Clarkson, R. S. Dickins, S. Faulkner, D. Parker, L. Royle, A. S. de Sousa, J. A. G. Williams, M. Woods, J. Chem. Soc. Perkin Trans. 2 1999, 493-503.

[21] H. Lammers, F. Maton, D. Pubanz, M. W. van Laren, H. van Bekkum, A. E. Merbach, R. N. Muller, J. A. Peters, Inorg. Chem. 1997, 36, $2527-$ 2538

[22] J. A. Peters, Contrast Media Mol. Imaging 2016, 11, 160-168.

[23] S. Aime, M. Botta, S. G. Crich, G. Giovenzana, R. Pagliarin, M. Sisti, E. Terreno, Magn. Reson. Chem. 1998, 36, S200-S208.

[24] M. Regueiro-Figueroa, C. Platas-Iglesias, J. Phys. Chem. A 2015, 119 6436-6445.

[25] P. Caravan, J. C. Amedio, Jr., S. U. Dunham, M. T. Greenfield, N. J. Cloutier, S. A. McDermid, M. Spiller, S. G. Zech, R. J. Looby, A. M. Raitsimring, T. J. McMurry, R. B. Lauffer, Chem. Eur. J. 2005, 11 5866-5874.

[26] L. Moriggi, C. Cannizzo, C. Prestinari, F. Berrière, L. Helm, Inorg Chem. 2008, 47, 8357-8366.

[27] S. Karimi, G. Hunter, L. Moriggi, C. Platas-Iglesias, L. Helm, Inorg Chem. 2016, 55, 6231-6239. 


\section{Entry for the Table of Contents}

\section{COMMUNICATION}

An apparently innocent change in the arrangement of the ligand donor atoms around the central $\mathrm{Ln}^{3+}$ ion has profound consequences in the thermodynamic stability and dissociation and water exchange kinetics of the complexes
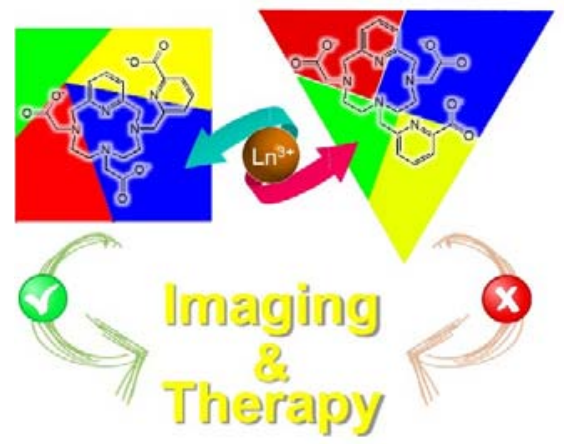

M. Le Fur, E. Molnár, M. Beyler, F. K. Kálmán, O. Fougère, D. EstebanGómez, O. Rousseaux, R. Tripier, Gy. Tircsó, ${ }^{*}$ and C. Platas-Iglesias*

\section{Page No. - Page No.}

A Coordination Chemistry Approach to Fine-Tune the Physicochemical Parameters of Lanthanide Complexes Relevant to Medical Applications 